\title{
Preparation and Properties of Novel Biodegradable Hydrogel based on Cationic Polyaspartamide Derivative
}

\author{
Jong Rok Moon, Bong Sup Kim, and Ji-Heung Kim" \\ "Polymer Technology Institute, Department of Chemical Engineering, Sunghyuntwan University, Sitwon, \\ Kytnggi 440-746, Korea. "E-mail: kimjh@skku.edu \\ Received April 17, 2006
}

\begin{abstract}
Novel copolymers consisting of poly(2-hydroxyethyl aspartamide-co- $N, N^{\prime}$-dimethyl-1,3-propane aspartamide) (PII $\Lambda$-DP $\Lambda$ ) were prepared from polysuccinimide (PSI), which is the thermal polycondensation product of aspartic acid, via a ring-opening reaction with $N_{N} N^{\prime}$-dimethyl-1,3-propane diamine (DP $\Lambda$ ) and ethanolamine. The prepared water-soluble copolymer was then crosslinked by reacting it with hexamethylene diisocyanate to provide the corresponding gel. The swelling behavior and morphology of the crosslinked hydrogels were investigated. The degree of swelling decreased with increasing crosslinking reagent due to the higher crosslinking density. It was also confirmed that the swelling property is affected by pIL $\Lambda \mathrm{t}$ low pII $(<\mathrm{pII} 4)$, swelling is increased due to the ionization of DP $\Lambda$ with a tertiary amine moiety. In addition, a reversible swelling and de-swelling behavior was demonstrated by adjusting the pII of the solution. The prepared hydrogels showed a well-interconnected microporous structure with regular $5-20 \mu \mathrm{m}$ sized pores.
\end{abstract}

Key Words : Polyaspartamide, Graft copolymer, Biodegradable polymer, Hydrogel, Swelling

\section{Introduction}

Hydrogels are hydrophilic polymer networks that are capable of absorbing large amounts of water, yet are insoluble due to the presence of physical or chemical crosslinks, entanglements, or crystalline regions. Hydrogels can be used in various biomedical applications such as drug delivery systems, biosensors, contact lenses, catheters, and wound dressings. These materials have also been used extensively as matrices in tissue engineering for repairing and regenerating a wide range of tissues and organs on account of their hydrophilic character and potential biocompatiblity. ${ }^{1,2}$ Hydrogels are known as chemical gels when they are covalently-crosslinked networks. Chemical hydrogels can be generated by the crosslinking of water-soluble polymers. In the crosslinked state, the hydrogels reach an equilibrium swelling level in aqueous solutions depending on the crosslink density (estimated by the MW between crosslinks, Mc). Recently, stimuli-responsive polymers have become increasingly attractive for biotechnology and medicines. ${ }^{3}$ Responsive hydrogels are smart materials that are capable of changing volume in response to specific external stimuli, such as temperature, $\mathrm{pH}$, electric field, etc.

Poly(aspartic acid) (PASP) is a promising water-soluble and biodegradable polymer that can be produced from the hydrolysis of poly(succinimide) (PSI). ${ }^{4-6} \mathrm{PSI}$, the precursor polymer, is prepared by the thermal bulk polycondensation of aspartic acid or the ammonium salts of maleic and malic acid. PASP consists of racemic aspartic acid residues with approximately 70 to $75 \%$ and 20 to $25 \%$ of $\alpha$ and $\beta$ linkages, respectively. PASP becomes highly absorbent when neutralized and crosslinked, and is $\mathrm{pH}$ and electrolyte sensitive in water and body fluids. ${ }^{7-10} \alpha, \beta$-Poly $(N-2$-hydr-
oxyethyl-DL-aspartamide), PHEA, is another important polymer, derived by coupling PSI with ethanolamine, which has potential as a plasma extender and a carrier for macromolecular prodrugs. ${ }^{11-14}$ The presence of hydroxyl groups in the side chain provides sites for forming a covalent linkage between the polymer and drug molecules or crosslinking reagents. This polymer has been demonstrated to have suitable physico-chemical characteristics for the development of macromolecular prodrugs, including biodegradability, high water solubility, and excellent biocompatibility. In addition, the PSI backbone can be easily modified to form hydrophilic-hydrophobic copolymers. Recently, many groups have reported the hydrophobic modification of PASP by grafting a hydrophobic alkyl chain onto the backbone of PSI polymers using aminolysis procedure. Therefore, long chain alkyl units can interact with each other to form intermolecular and intramolecular hydrophobic microdomains in water as a result of the self-aggregation of these copolymers. ${ }^{15-17}$

Recently, we examined the preparation and properties of biodegradable copolymers and their crosslinked hydrogels based on poly(aspartic acid) and poly(2-hydroxyethyl aspartamide), ${ }^{8,9,18-20}$ Also several other groups have reported papers on the thermoresponsive hydrogels based on polyaspartamide and the derivative polymers. ${ }^{21-25}$ This paper reports the preparation of novel copolymers consisting of poly(2-hydroxyethyl aspartamide-co- $N N^{\prime}$-dimethyl-3-aminopropyl aspartamide) (PHEA-DPA) from PSI, via a ringopening reaction with $N N^{\prime}$-dimethyl-1,3-propane diamine (DPA) and ethanolamine followed by a crosslinking reaction with different amounts of hexamethylene disiocyanate. The pH-responsive swelling behavior and morphology of the PHEA-DPA crosslinked gels were investigated. 


\section{Experimental Section}

Materials. L-aspartic acid $(98+\%), o$-phosphoric acid $(98 \%), N, N^{\prime}$-dimethyl-1,3-propanediamine (DPA, 99\%), ethanolamine (EA, 99\%), hexamethylene diisocyanate (HMDI, 98\%), dibutyltin dilaurate $(95 \%)$, and $N, N$-dimetylformamide (DMF, Anhydrous 99.8\%) were purchased from Aldrich Chemical Co. and used as received. Diethylether (99\%) was obtained from DaeJung Chemical Co. (Korea) and used after distillation. Buffer $\mathrm{pH}$ solutions for swelling measurement were purchased from Aldrich Chemical Co. The dialysis membrane (Spectra/pore4 with MWCO 1214,000 ) was used to eliminate any unreacted monomer and solvent.

Measurements. ${ }^{1} \mathrm{H}-\mathrm{NMR}$ spectra were recorded on a Bruker AMX-500 spectrometer using $\mathrm{D}_{2} \mathrm{O}$ as the solvent. The FT-IR spectra were obtained on a PerkinElmer FT-IR spectrometer (Model SPECTRUM 2000). The themal analyses were carried out on a PerkinElmer DSC/TGA7 Series thermal analysis system at the heating rate of $10^{\circ} \mathrm{C} /$ $\min$ in nitrogen. The morphology of the prepared gel scaffolds was observed by scanning electron microscopy (ESEM Model XL30 ESEM-FEG, Phillips). A porous gel sample were mounted onto a metal stub with double-sided carbon tape and coated with $\mathrm{Pt}$ for $30 \mathrm{~s}$ under vacuum $\left(10^{-3}\right.$ Torr) using a plasma sputtering method (Ion sputter coater $\mathrm{HC}-21$ ).

Syntheis of Polysuccinimide (PSI). L-aspartic acid (20 g) and $o$-phosphoric acid $(20 \mathrm{~g})$ were charged into a roundbottom flask and stirred under reduced pressure at $200^{\circ} \mathrm{C}$ for $5 \mathrm{~h}$. The reaction mixture was then cooled and DMF was added to dissolve the product. The resulting solution was precipitated in excess water and the precipitate was washed several times with water to remove the residual phosphoric acid. The final product was dried at $80^{\circ} \mathrm{C}$ under vacuum. The prepared PSI had a reduced viscosity of $0.52 \mathrm{dL} / \mathrm{g}$ in DMF. The molecular weight was estimated to be approximately $160,000 \mathrm{Da}$, as calculated from an empirical equation relating the solution viscosity to the molecular weight. ${ }^{4}$

Synthesis of Poly $\left(N, N^{\prime}\right.$-dimethyl-3-aminopropyl aspartamide) (PDPA). $1 \mathrm{~g}$ of PSI was dissolved in $10 \mathrm{~mL}$ DMF in a round-bottom flask, and an equimolar amount of, $N, N^{\prime}$-dimethyl-1,3-propanediamine (DPA) was then added dropwise at $0^{\circ} \mathrm{C}$. The reaction flask was then placed in a water bath at $25^{\circ} \mathrm{C}$. After stirring for $24 \mathrm{~h}$, the solution was precipitated into 10 -fold ethylether. The filtered precipitate of the PDPA polymer was dissolved in water and dialyzed using the membrane (MWCO 12,000-14,000) to remove the unreacted monomer and residual solvent. Finally, the dialysis product was freeze-dried over a 3 -day period. (yield $80 \%$ )

${ }^{1} \mathrm{H}-\mathrm{NMR}\left(500 \mathrm{MHz}, \mathrm{D}_{2} \mathrm{O}\right): \delta 2.5-2.9\left(\mathrm{~m}, 2 \mathrm{H}, \mathrm{CH}-\mathrm{CH}_{2}-\right.$ $\mathrm{CO}-\mathrm{NH}), 4.56-4.7\left(\mathrm{~m}, 1 \mathrm{H}, \mathrm{NH}-\mathrm{CH}-\mathrm{CO}-\mathrm{CH}_{2}\right), 3.1-3.26$ (br, $\left.2 \mathrm{H}, \mathrm{NH}-\mathrm{CH}_{2}-\mathrm{CH}_{2}-\mathrm{CH}_{2}-\mathrm{N}-\left(\mathrm{CH}_{3}\right)_{2}\right), 1.56-1.76$ (br, $2 \mathrm{H}, \mathrm{NH}-$ $\mathrm{CH}_{2}-\mathrm{CH}_{2}-\mathrm{CH}_{2}-\mathrm{N}-\left(\mathrm{CH}_{3}\right)_{2}$ ), 2.2-2.5 (br, $2 \mathrm{H}, \mathrm{NH}-\mathrm{CH}_{2}-\mathrm{CH}_{2}-$ $\left.\mathrm{CH}_{2}-\mathrm{N}-\left(\mathrm{CH}_{3}\right)_{2}\right), \quad\left(\mathrm{br}, 6 \mathrm{H}, \quad \mathrm{NH}-\mathrm{CH}_{2}-\mathrm{CH}_{2}-\mathrm{CH}_{2}-\mathrm{N}-\left(\mathrm{CH}_{3}\right)_{2}\right)$, Figure 1(A).
Synthesis of the PHEA-DPA Copolymer. $1 \mathrm{~g}$ of PSI was dissolved in $10 \mathrm{~mL}$ DMF in a 3 -neck round-bottom flask. 70 mol\% of $N, N^{\prime}$-dimethyl-1,3-propanediamine (DPA) was then added dropwise at $0^{\circ} \mathrm{C}$. Subsequently, the reaction flask was placed in a water bath controlled at $25^{\circ} \mathrm{C}$ and stirred for $24 \mathrm{~h} .50 \mathrm{~mol} \%$ (excess) of ethanolamine (EA) was then slowly added to the solution and stirred for another $24 \mathrm{~h}$. The final solution was then precipitated into a 10 -fold ether solvent. The filtered precipitate of the poly(2-hydroxyethyl aspartamide-co- $N, N^{\prime}$-dimethyl-3-aminopropyl aspartamide) (PHEA-DPA) copolymers were dialyzed using the membrane (MWCO 12,000-14,000) to remove any unreacted monomer and residue solvent. Finally, the dialysis product was freeze-dried to give an "off-white" powder (yield $83 \%$ ).

'H-NMR ( $500 \mathrm{MHz}, \mathrm{D}_{2} \mathrm{O}$ ): $\delta 2.6-2.9$ (br, $2 \mathrm{H}, \mathrm{CH}-\mathrm{CH}_{2}-$ $\mathrm{CO}-\mathrm{NH}$ ), $4.5-4.7$ (m, 1H, NH-CH-CO-CH ), 3.1-3.26 (br, $\left.2 \mathrm{H}, \mathrm{NH}-\mathrm{CH}_{2}-\mathrm{CH}_{2}-\mathrm{CH}_{2}-\mathrm{N}-\left(\mathrm{CH}_{3}\right)_{2}\right), 1.56-1.76$ (br, $2 \mathrm{H}, \mathrm{NH}-$ $\left.\mathrm{CH}_{2}-\mathrm{CH}_{2}-\mathrm{CH}_{2}-\mathrm{N}-\left(\mathrm{CH}_{3}\right)_{2}\right), 2.2-2.5$ (br, $2 \mathrm{H}, \mathrm{NH}-\mathrm{CH}_{2}-\mathrm{CH}_{2}-$ $\left.\mathrm{CH}_{2}-\mathrm{N}-\left(\mathrm{CH}_{3}\right)_{2}\right) \quad\left(\right.$ br, $6 \mathrm{H}, \quad \mathrm{NH}-\mathrm{CH}_{2}-\mathrm{CH}_{2}-\mathrm{CH}_{2}-\mathrm{N}-\left(\mathrm{CH}_{3}\right)_{2}$ ), 3.56-3.63 (br, $2 \mathrm{H}, \mathrm{NH}-\mathrm{CH}_{2}-\mathrm{CH}_{2}-\mathrm{OH}$ ), 3.27-3.3 (br, 2H, NH$\left.\mathrm{CH}_{2}-\mathrm{CH}_{2}-\mathrm{OH}\right)$, Figure 1(B).

Synthesis of PHEA-DPA Crosslinked Hydrogel. The prepared PHEA-DPA copolymer $1 \mathrm{~g}$ was dissolved in $10 \mathrm{~mL}$ DMF in a round-bottom flask at $60^{\circ} \mathrm{C}$. Each $60,80,100$ and $120 \mathrm{~mol} \%$ amount (based on hydroxyl groups on the structure) of HMDI, the crosslinking agent, and $0.5 \mathrm{wt} \%$ of dibutyltin diaurate, as the catalyst, were added to the solution using a microsyringe and the reaction mixture was stirred for $24 \mathrm{~h}$. The solution became gradually viscous and turned into a gel-like state. The resulting PHEA-DPA crosslinked gel was placed in a steel mesh and washed with a large amount of water for 2 days in order to completely remove the unreacted components and DMF solvent. Finally, the washed gel product was freeze-dried under vacuum (yield $80 \%$ ).

Measurement of Swelling Capacity. The water absorbance (degree of swelling) of the above-prepared hydrogels was measured by gravimetric analysis. First, the dried samples $\left(c a .50 \mathrm{mg}\right.$ ) were placed in distilled water at $25^{\circ} \mathrm{C}$ and removed from the water at regular intervals. The weights of the hydrogels were recorded after wiping off the water on the surfaces of the hydrogels with moistened filter paper. The degree of swelling (swelling ratio) was defined as follows:

Degree of Swelling $=W_{s} / W_{d}$

Where, $W_{d}$ and $W_{s}$ are the weight of the dry and swollen hydrogels at time, $\mathrm{t}$.

\section{Results and Discussion}

Poly $\left(N, N^{\prime}\right.$-dimethyl-3-aminopropyl aspartamide) (PDPA) and Poly(2-hydroxyethyl-co- $N, N^{\prime}$-dimethyl-3-aminopropyl aspartamide) (PHEA-DPA), as novel cationic polyaspartamide derivatives, were prepared from polysuccinimide (PSI), which is the themmal polycondensation product of aspartic acid, via an aminolysis reaction with $N, N^{\prime}$-dimethyl- 


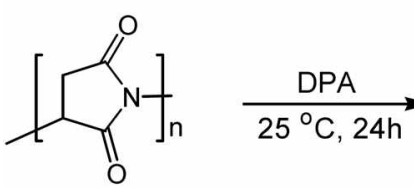

PSI

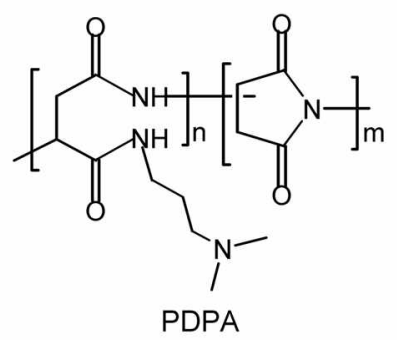

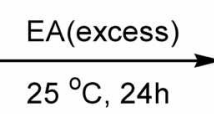<smiles>CC(C)C(=O)NCCCNC(=O)CC(C)(C)CC(=O)NCCCO</smiles>

PHEA-DPA

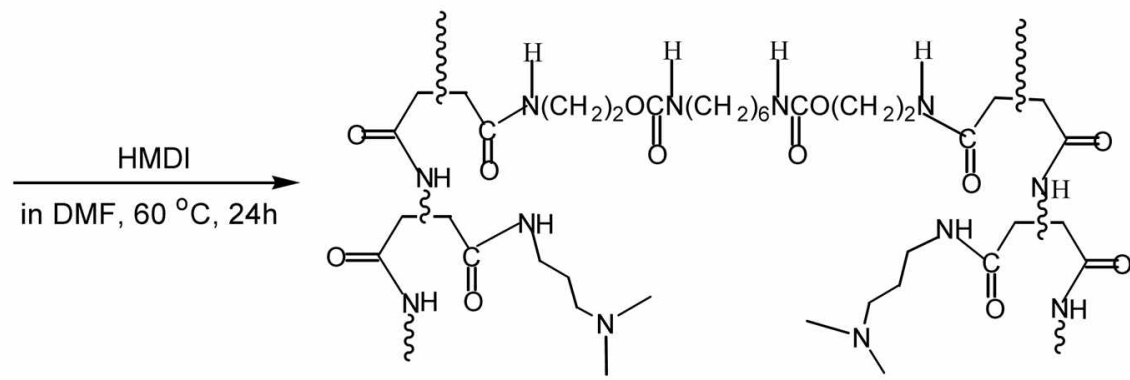

PHEA-DPA gel

Scheme 1

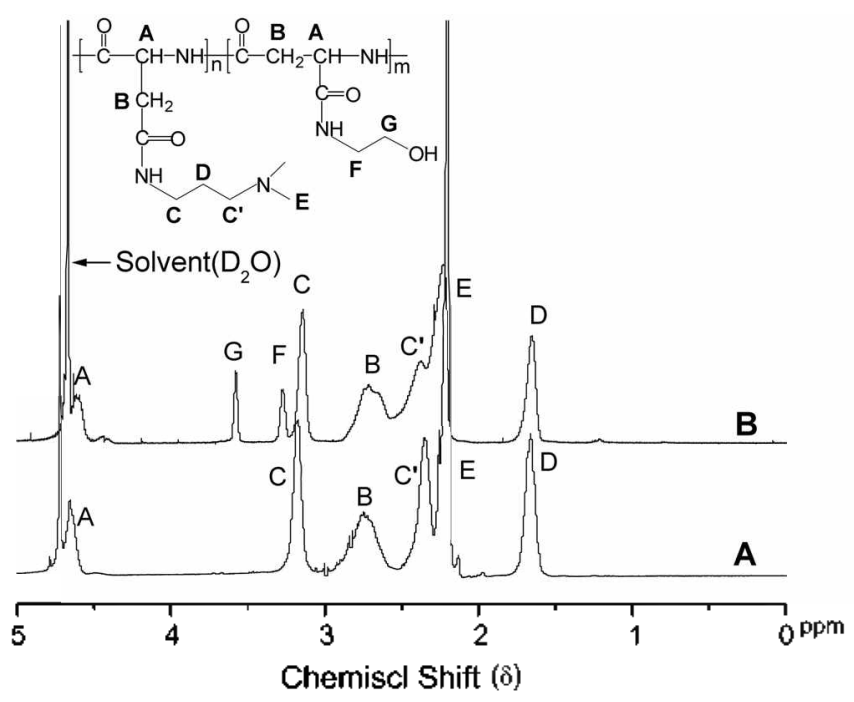

Figure 1. 'H-NMR spectra of PDPA $(\Lambda)$ and PHE $\Lambda$-DPA $(B)$.

1,3-propane diamine (DPA) and ethanolamine (EA). The crosslinked gels were prepared from PHEA-DPA via a crosslinking reaction through the hydroxyl moiety (see Scheme 1). Although dialdehyde (ex. glutaldehyde) or dissocyanate compounds are among the most common crosslinking reagent, hexamethylene dijsocyanate was used in this study.

Figure 1 shows the 'H-NMR spectra of the PDPA (A) and PHEA-DPA (B) copolymers. As shown in Figure 1 , the proton peaks $\mathrm{C}, \mathrm{C}, \mathrm{D}$, and $\mathrm{E}$ were assigned to the DPA pendants, and the $F$ and $G$ peaks were related to two methylene protons of the EA pendants. The composition of each group in the PHEA-DPA copolymer was determined from the integration ratio between peaks $D$ and $G$. A typical copolymer with $20 \mathrm{~mol} \%$ EA content was used for the next gel preparation.

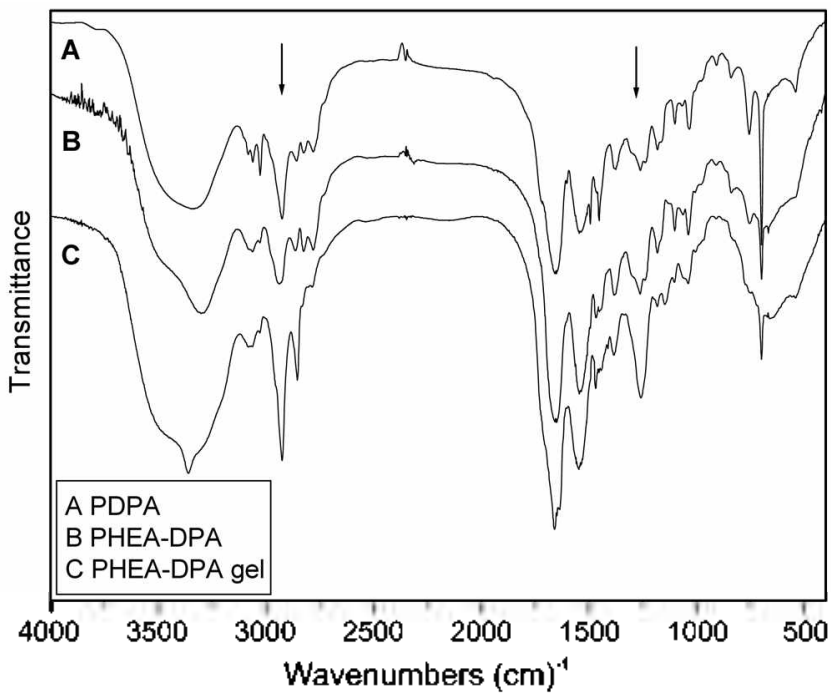

Figure 2. FT-IR spectra of PDPA (A), PHEA-DPA (B), and PHEADPA gel (C).

Figure 2 shows the FT-IR spectra of PDPA (A), PHEADPA copolymer (B) and PHEA-DPA crosslinked gel (C). The PDPA copolymer was prepared via an aminolysis reaction between PSI and DPA. As shown in Figure 2, spectrum (A) shows characteristic strong bands at $1649 \mathrm{~cm}^{-1}$ (amide I), $1545 \mathrm{~cm}^{-1}$ (amide II) and $3305 \mathrm{~cm}^{-1}$ (-NH-) corresponding to the aspartamide backbone structure, and the band at $2950 \mathrm{~cm}^{-1}$ corresponds to the $\mathrm{CH}_{2}$ stretching band appeared after the aminolysis reaction between PSI and DPA, On the other hand, spectrum (B) shows broad bands at $3400 \mathrm{~cm}^{-1}-3100 \mathrm{~cm}^{-1}$ (-OH stretching). Spectrum (C) shows additional characteristic bands that were assigned to urethane groups. New strong bands at $1250 \mathrm{~cm}^{-1}$ and 1100 $\mathrm{cm}^{-1}$, which were assigned to $\mathrm{C}-\mathrm{N}$ and $\mathrm{C}-\mathrm{O}$ stretching, with stronger alkylene absorption band at $2950 \mathrm{~cm}^{-1}$ were 


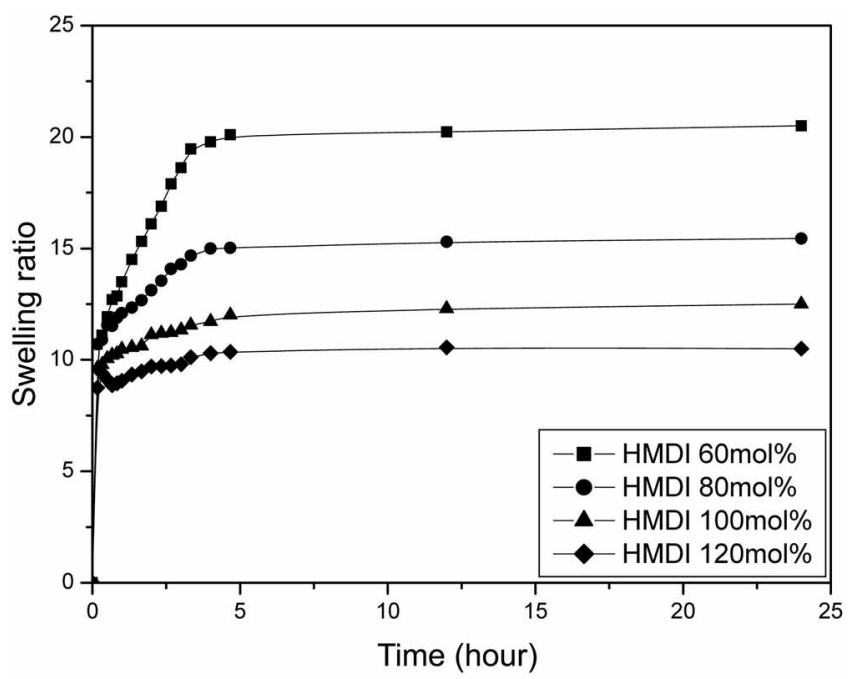

Figure 3. Typical swelling curves of gels in pure water at $25^{\circ} \mathrm{C}$.

observed. FT-IR and 'H-NMR analyses indicated that the PDPA and PHEA-DPA copolymers had been prepared successfully from the aminolysis reaction of PSI.

Themal analysis of the PDPA and PHEA-DPA under nitrogen showed Tg's of the polymer at 62 and $65{ }^{\circ} \mathrm{C}$ respectively, as detemnined by the mid-point of the baseline change in DSC. These polymers were stable up to ca. $200^{\circ} \mathrm{C}$ without any weight loss.

Figures 3 and Figure 4 show the swelling of the prepared gels as a function of the level of HMDI, the crosslinking reagent, in pure water and the phosphate buffered saline (PBS) solution, respectively. The prepared gels were tested to determine their swelling properties in aqueous solutions using the tea-bag method, and the level of water absorbency was measured as a function of time. As shown in Figure 3, the initial fast swelling behavior appeared to level off after 3-5 $\mathrm{h}$ in pure water. The swelling ratios were controlled to be in the range of $c a .10-20$ by varying the amount of HMDI. The degree of swelling decreased with increasing crosslinking agent due to the higher crosslinking density (estimated by

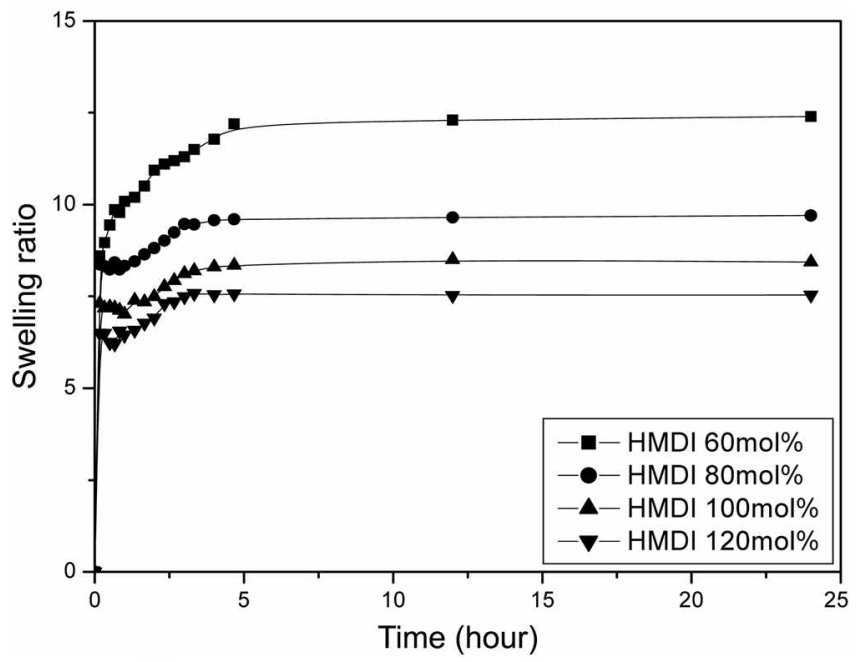

Figure 4. Typical swelling curves of gels in PBS (pH 7.4) at $25^{\circ} \mathrm{C}$.

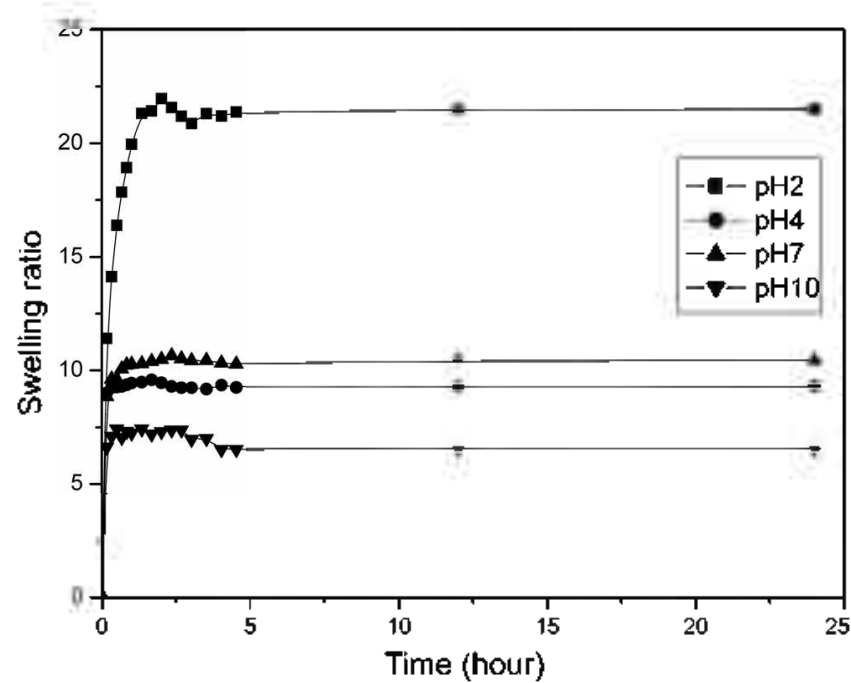

Figure 5. Swelling dependence on the $\mathrm{pH}$ of buffer solutions at 25 ${ }^{\circ} \mathrm{C}$.

the MW between crosslinks, Mc). The degree of swelling in the PBS ( $\mathrm{pH} \mathrm{7.4)} \mathrm{solution} \mathrm{decreased} \mathrm{to} \mathrm{some} \mathrm{extent,} \mathrm{as}$ shown in Figure 4 . The swelling ratios ranged from $7-14$, corresponding to approximately $70 \%$ compared to those in pure water. This might be due to the increase in jonic strength of the hydrogels on account of the jonization of DPA with pendant tertiary amine groups. There was a similar dependence of the absorbency in PBS ( $\mathrm{pH} \mathrm{7.4)} \mathrm{on}$ the amount of the crosslinking agent to that observed in water.

Figure 5 shows the water absorbency in the different buffered $\mathrm{pH}$ solutions. Due to the presence of basic tertiary amine pendants on the polymer structure, the swelling behavior of the prepared gel can be affected by $\mathrm{pH}$. At $\mathrm{pH} 2$ the degree of swelling increased significantly due to ionization

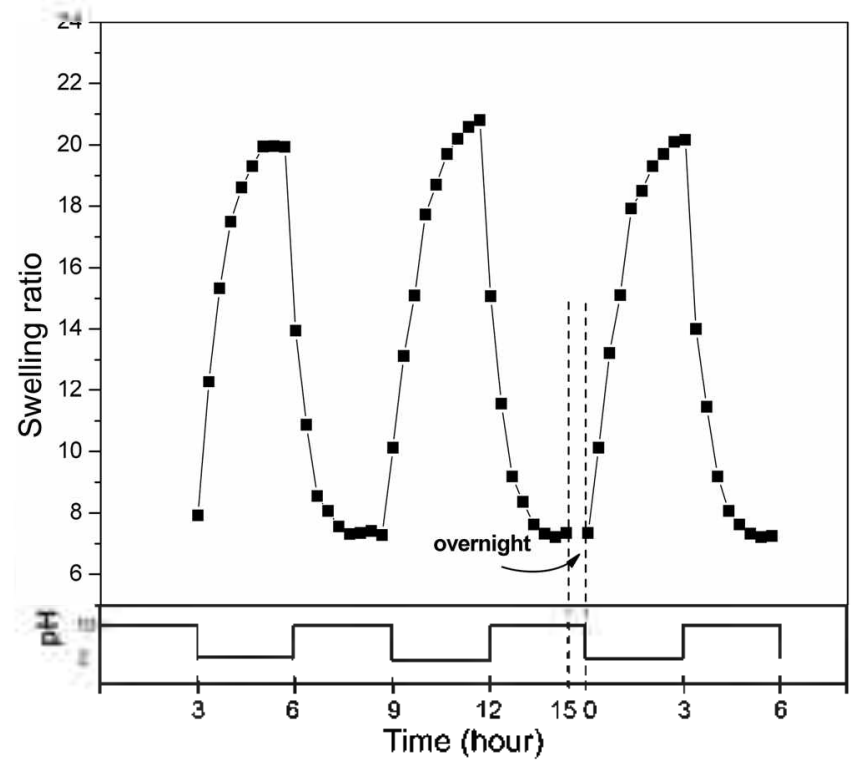

Figure 6. Reversible swelling and deswelling behavior of the hydrogel. 


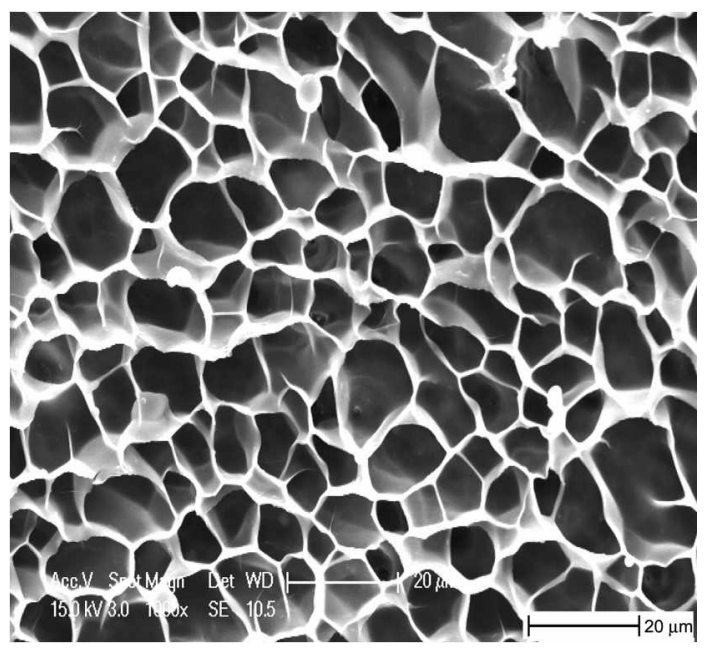

Figure 7. SEM image of freeze-dried PHEA-DPA hydrogel.

of the tertiary amine. The degree of swelling was lower at neutral and alkaline $\mathrm{pH}$. Figure 6 shows the pulsatile swelling behavior of the PHEA-DPA crosslinked gel with $\mathrm{pH}$ altemating between $\mathrm{pH} 2$ and $\mathrm{pH} 10$. A reversible swelling and deswelling behavior was observed. As shown in Figure 5, the degree of swelling changed with $\mathrm{pH}$, showing maximum $\mathrm{pH} 2$ and minimum $\mathrm{pH} 10$. After standing ovenight at $\mathrm{pH} 10$, a reversible swelling behavior was demonstrated in the same manner.

Figure 7 shows an SEM image of a typical freeze-dried PHEA-DPA crosslinked gel (HMDI $100 \mathrm{~mol} \%$ sample). A well-interconnected microporous structure with 5-15 $\mu \mathrm{m}$ sized pores was observed. However, there was no appreciable difference in pore size among different gels prepared in this study. Further study on pore size control in this gel system is currently underway. Because of the many advantageous properties of the polyaspartamide polymers including biodegradability and biocompatibility, this PHEA-DPA hydrogel is potentially useful for biomedical applications such as tissue engineering and smart delivery systems.

\section{Conclusion}

Novel hydrogels consisting of PHEA-DPA were prepared from PSI via a ring-opening reaction with DPA and EA followed by a crosslinking reaction with HMDI. Hydrogels with a degree of swelling ranging from $10-20 \mathrm{~g} / \mathrm{g}$ in water were obtained by varying the crosslinking density. It was confirmed that the swelling property was sensitive $\mathrm{pH}$ due to the ionization of DPA having a pendant tertiary amine. In addition, a reversible swelling and deswelling behavior of the gels was observed. The prepared hydrogels showed a well-interconnected network structure with regularly spaced micron-size pores.

Acknowledgment. This work was supported by the Korea Research Foundation Grant (KRF-2004-005-D00070).

\section{References}

I. Langer, R.; Peppas, N. A. AIChE Journal 2003, 49(12), 2990.

2. Lee, K. Y.; Mooney, D. J. Chem. Rev. 2001, 101, 1869.

3. Gil, E. S.; Hudson, S. M. Prog. Polym. Sci. 2004, 29, 1173.

4. Neri, P; Antoni, G.; Benvenuti, F.; Colola, F.; Gazzei, G. J. Med. Chen. 1972, 16, 893.

5. Wolk, S. K.; Swif, G.; Paik, Y. H.; Yocom, K. M.; Smith, R. L.; Simon, E. S. Macromolectles 1994, 27,7613.

6. Nakata, T.; Yoshitake, M.; Matsubara, K.; Tomida, M.; Kakuchi, T. Macromolectles 1998, 31, 2107.

7. Andrade, J. D. Hydrogels for Medical and Related Application, ACS Symp. Ser. No. 631; American Chemical Society: Washington, D.C. 1996.

8. Min, S. K.; Kim, J.-H. Korean Polym. J. $2001,9,143$.

9. Kim, J.-H.; Lee, J. H.; Yoon, S.-W. J. Ind. Eng. Chem, 2002, \&, 138.

10. Yoshimura, T.; Ochi, Y,; Fujioka, R. Polymer Bulletin 2005, 55, 377.

11. Pitarresi, G.; Tomarchio, V.; Cavallaro, G.; Giammona, G. $J$. Bioact. Conipat. Polym. 1996, II, 328.

12. Caldwell, G; Nense, E. W; Perlwitz, A. Z. J. Appl. Polym. Sci. $1997,66,911$.

13. Van der Merwe, T.; Boneschans, B.; Zore, B.; Breylenbach, J.; Zovko, M. International Journal of Pharmaceutics 2002, 24l, 223.

14. Gavallaro, G.; Licciardi, M.; Giammona, G.; Caliceti, P.; Semenzato, A.; Salmaso, S. Jotrnat of Controlled Release 2003, 89, 285.

15. Mendichi, R.; Schieroni, A. G.; Cavallaro, G.; Licciardi, M.; Giammona, G Polymer 2003, 44, 4871.

16. Jeong, J. H.; Kang, H. S.; Yang, S. R.; Kim, J. Polymer 2003, 44, 583.

17. Pitaresi, G.; Pierro, P.; Giammona, G.; Iemma, F.; Muzzalupo, R.; Picci, N. Biomaterial 2004, 25, 4333.

18. Kim, J. H.; Sim, S. J.; Lee, D. H.; Kim, D.; Lee, Y. K.; Chung, D. J.; Kim, J.-H. Polymer J, 2004, 36,943.

19. Kim, J. H.; Sim, S. J.; Lee, D. H.; Kim, D.; Lee, Y. K.; Kim, J.-H. Polmer(Korea) 2005, 29, 518.

20. Yoon, S. W.; Chung, D. J.; Kim, J.-H. J. Appl. Polym. Sci. 2003, 90,3741 .

21. Tachibana, Y,; Kurisawa, M.; Uyama, H.; Kakuchi, T.; Kobayshi, S. Chem, Lett. 2003, 32(4), 374.

22. Tachibana, Y,; Kurisawa, M.; Uyama, H.; Kakuchi, T.; Kobayshi, S. Chem. Conm. 2003, 106.

23. Takeuchi, Y.; Uyama, H.; Tomoshige, N.; Watanabe, E.; Tachibana, Y.; Kobayashi, S. J. Polym. Sci., Pohm. Chem. 2006, 44, 671 .

24. Chen, H.; Xu, W; Chen, T;; Yang, W.; Hu, J.; Wang, C. Polymer $2005,46,1821$.

25. Walanabe, E.; Tomoshige, N. Chem, Lett. 2005, 34(6), 876. 